\title{
Association between colon diverticula and hemoglobin, triglyceride and uric acid levels
}

\author{
MINORU TOMIZAWA ${ }^{1}$, FUMINOBU SHINOZAKI ${ }^{2}$, RUMIKO HASEGAWA $^{3}$, YOSHINORI SHIRAI ${ }^{3}$, \\ YASUFUMI MOTOYOSHI ${ }^{4}$, TAKAO SUGIYAMA ${ }^{5}$, SHIGENORI YAMAMOTO ${ }^{6}$ and NAOKI ISHIGE $^{7}$
}

Departments of ${ }^{1}$ Gastroenterology, ${ }^{2}$ Radiology, ${ }^{3}$ Surgery, ${ }^{4}$ Neurology, ${ }^{5}$ Rheumatology, ${ }^{6}$ Pediatrics and ${ }^{7}$ Neurosurgery, National Hospital Organization Shimoshizu Hospital, Yotsukaido, Chiba 284-0003, Japan

Received December 23, 2014; Accepted September 24, 2015

DOI: $10.3892 / \mathrm{etm} .2015 .2804$

\begin{abstract}
Colon diverticula cause bleeding and acute diverticulitis. The present study analyzed laboratory test variables, aiming to predict the presence of diverticula. Patient records from between April 2011 and March 2014 were analyzed retrospectively (1,520 patients) and a one-way analysis of variance was performed to analyze the association between the presence of diverticula and each variable. A $\chi^{2}$ test was then used to assess the correlation between the prevalence of diverticula and the percentage of patients with uric acid (UA) levels $\geq 5.1 \mathrm{mg} / \mathrm{dl}$. A receiver operating characteristic (ROC) analysis was performed to determine the threshold values required to predict the presence of diverticula. Hemoglobin (Hb) levels were lower in patients with diverticula than in those without diverticula $(\mathrm{P}=0.0027)$, and compared with patients without diverticula, UA and triglyceride (TG) levels were higher in patients with diverticula $(\mathrm{P}=0.0066$ and $\mathrm{P}=0.0136$, respectively). The patients were divided into two groups, as follows: Patients with UA levels $\geq 5.1 \mathrm{mg} / \mathrm{dl}$ (the median value) and those with UA levels $<5.1 \mathrm{mg} / \mathrm{dl}$. The prevalence of diverticula was significantly higher in patients with UA levels $\geq 5.1 \mathrm{mg} / \mathrm{dl}$ than in those with UA levels $<5.1 \mathrm{mg} / \mathrm{dl}(\mathrm{P}=0.0004)$. ROC analysis demonstrated that the threshold values of $\mathrm{Hb}$, TG and UA were $12,400,146$ and $5.1 \mathrm{mg} / \mathrm{dl}$, respectively. The sensitivity of the $\mathrm{Hb}$ and UA levels at the threshold values was 76.5 and $71.0 \%$, respectively. The prevalence of diverticula was associated with low Hb levels, and high TG and UA levels.
\end{abstract}

\section{Introduction}

Colon diverticula are outpouchings of the mucosa and muscularis mucosa. Diverticula develop where the colon wall

Correspondence to: Dr Minoru Tomizawa, Department of Gastroenterology, National Hospital Organization Shimoshizu Hospital, 934-5 Shikawatashi, Yotsukaido, Chiba 284-0003, Japan E-mail: nihminor-cib@umin.ac.jp

Key words: one-way analysis of variance, receiver-operating characteristic analysis, uric acid, triglycerides is weak (1), the negative outcomes of which are bleeding and acute diverticulitis $(2,3)$. Bleeding from diverticula accounts for $20-50 \%$ of lower gastrointestinal bleeding cases (4); this is usually self-limiting, but is occasionally fatal for patients taking non-steroidal anti-inflammatory drugs and anticoagulants (5-7). Acute diverticulitis is treated with antibiotics (8), which can cause complications, and surgery is required if diverticulum perforation occurs (9). The risk of bleeding and perforation may be reduced if the presence of diverticula is identified in advance.

Studies on the risks of diverticula predominantly focus on aging, genetic factors and dietary fiber. The odds ratio of siblings with diverticula is 7.15 for monozygotic twins and 3.2 for dizygotic twins (10). Among the cases of diverticula, $40 \%$ result from inherited factors and $60 \%$ from environmental factors (10). However, controversy remains over whether dietary fiber is one of the causes $(11,12)$. Crowe et al (11) concluded that increased dietary fiber intake decreases the risk of diverticula, but Peery et al (12) reported that fiber intake does not affect the prevalence of diverticula. With regard to risk factors, Song et al (13) attributed aging, high-fat diets and high alcohol consumption as factors increasing the risk of diverticula.

If laboratory data that are correlated with the presence of diverticula were available, it would be possible to develop strategies to decrease the risk of developing diverticula; the present study therefore analyzed the laboratory data of patients who underwent colonoscopy in order to determine variables that predict the presence of diverticula.

\section{Materials and methods}

Patients. Patient records from between April 2011 and March 2014 were analyzed retrospectively. A total of 1,520 patients underwent colonoscopy and were included in the analysis, including 758 men (mean age \pm standard deviation, $68.9 \pm 10.9$ years) and 762 women (68.7 \pm 10.8 years). The current study was approved by the National Hospital Organization Shimshizu Hospital Ethics Committee (Yotsukaido, Japan) and was not categorized as a clinical trial as it was performed during routine clinical practice. Written informed consent was waived since the present study was retrospective. Patient anonymity was preserved. 
Table I. Blood variable differences in patients with and without colon diverticula.

\begin{tabular}{|c|c|c|c|c|c|c|}
\hline Variable & $\begin{array}{l}\text { Total number } \\
\text { of patients }\end{array}$ & $\begin{array}{l}\text { Patients without } \\
\text { colon diverticula, } \mathrm{n}\end{array}$ & $\begin{array}{l}\text { Variable level, } \\
\text { mean } \pm \mathrm{SD}\end{array}$ & $\begin{array}{c}\text { Patients with } \\
\text { colon diverticula, } \mathrm{n}\end{array}$ & $\begin{array}{c}\text { Variable level, } \\
\text { mean } \pm \mathrm{SD}\end{array}$ & P-value \\
\hline $\mathrm{WBC}, \mu 1$ & 743 & 563 & $6.06 \pm 2.06$ & 180 & $6.22 \pm 2.08$ & 0.3514 \\
\hline $\mathrm{Hb}, \mathrm{g} / \mathrm{dl}$ & 742 & 63 & $12.8 \pm 0.22$ & 179 & $1.24 \pm 0.20$ & 0.0027 \\
\hline CRP, mg/dl & 392 & 303 & $0.95 \pm 3.11$ & 89 & $0.69 \pm 1.63$ & 0.4452 \\
\hline Plt, $10^{4} / \mu 1$ & 734 & 554 & $2.23 \pm 0.73$ & 180 & $2.20 \pm 0.69$ & 0.6652 \\
\hline $\mathrm{TP}, \mathrm{g} / \mathrm{dl}$ & 492 & 370 & $6.89 \pm 0.68$ & 122 & $6.77 \pm 0.89$ & 0.1268 \\
\hline Alb, g/dl & 350 & 264 & $3.99 \pm 0.04$ & 86 & $4.02 \pm 0.06$ & 0.5985 \\
\hline T-Bil, mg/dl & 499 & 378 & $0.76 \pm 0.42$ & 121 & $0.75 \pm 0.33$ & 0.9497 \\
\hline ALP, IU/1 & 255 & 196 & $2.38 \pm 1.02$ & 59 & $2.23 \pm 0.59$ & 0.2807 \\
\hline AST, IU/1 & 677 & 511 & $2.46 \pm 1.33$ & 166 & $2.66 \pm 3.30$ & 0.2617 \\
\hline ALT, IU/1 & 713 & 545 & $2.16 \pm 1.35$ & 168 & $2.53 \pm 3.87$ & 0.0591 \\
\hline$\gamma$-GTP, IU/1 & 290 & 225 & $0.51 \pm 2.24$ & 65 & $0.45 \pm 0.56$ & 0.8382 \\
\hline LDH, IU/1 & 379 & 297 & $2.06 \pm 1.04$ & 82 & $1.97 \pm 0.49$ & 0.4360 \\
\hline $\mathrm{UA}, \mathrm{mg} / \mathrm{d})$ & 282 & 213 & $5.13 \pm 1.46$ & 69 & $5.66 \pm 1.28$ & 0.0066 \\
\hline BUN, mg/dl & 469 & 353 & $1.61 \pm 1.46$ & 116 & $1.52 \pm 0.50$ & 0.5124 \\
\hline Cre, mg/dl & 713 & 545 & $0.84 \pm 0.39$ & 168 & $0.86 \pm 0.26$ & 0.6060 \\
\hline T-Chol, mg/dl & 286 & 222 & $2.01 \pm 0.38$ & 64 & $1.99 \pm 0.41$ & 0.6999 \\
\hline $\mathrm{TG}, \mathrm{mg} / \mathrm{dl}$ & 259 & 198 & $1.24 \pm 0.81$ & 61 & $1.53 \pm 0.77$ & 0.0136 \\
\hline $\mathrm{HDL}, \mathrm{mg} / \mathrm{dl}$ & 197 & 145 & $5.97 \pm 1.75$ & 52 & $5.68 \pm 1.59$ & 0.2982 \\
\hline $\mathrm{LDL}, \mathrm{mg} / \mathrm{dl}$ & 272 & 204 & $1.17 \pm 0.28$ & 68 & $1.21 \pm 0.29$ & 0.3834 \\
\hline $\mathrm{BG}, \mathrm{mg} / \mathrm{dl}$ & 375 & 294 & $1.19 \pm 0.40$ & 81 & $1.24 \pm 0.50$ & 0.3211 \\
\hline HbA1c, $\%$ & 180 & 139 & $6.17 \pm 0.94$ & 41 & $6.27 \pm 1.35$ & 0.5805 \\
\hline BMI, $\mathrm{kg} / \mathrm{m}^{2}$ & 273 & 212 & $2.25 \pm 0.36$ & 61 & $2.29 \pm 0.40$ & 0.4734 \\
\hline CEA, ng/ml & 208 & 167 & $1.61 \pm 7.68$ & 41 & $9.86 \pm 5.61$ & 0.0669 \\
\hline CA19-9, U/ml & 205 & 165 & $0.22 \pm 0.63$ & 40 & $0.66 \pm 3.20$ & 0.0984 \\
\hline
\end{tabular}

'Total number of patients' indicates the number of patients subjected to each laboratory test. WBC, white blood cell count; Hb, hemoglobin; CRP, C-reactive protein; Plt, platelet; TP, total protein; Alb, albumin; T-Bil, total bilirubin; ALP, alkaline phosphatase; AST, aspartate aminotransferase; ALT, alanine aminotransferase; $\gamma$-GTP, $\gamma$-glutamyl transpeptidase; LDH, lactate dehydrogenase; UA, uric acid; BUN, blood urea nitrogen; Cre, creatinine; T-Chol, total cholesterol; TG, triglyceride; HDL, high-density lipoprotein cholesterol; LDL, low-density lipoprotein cholesterol; BG, blood glucose; HbA1c, hemoglobin A1c; BMI, body mass index; CEA, carcinoembryonic antigen; CA19-9, carbohydrate antigen 19-9; SD, standard deviation.

Colonoscopy. A colonoscopy was performed for patients with abdominal symptoms, anemia or positive fecal occult blood. A colonoscopy was also performed for screening purposes. The colonoscopy devices used were CF-Q260DL/I and PCF-Q260AL/I (Olympus, Tokyo, Japan).

Blood variables. White blood cell count, platelet count, body mass index, and levels of hemoglobin ( $\mathrm{Hb}), \mathrm{C}$-reactive protein, total protein, albumin, total bilirubin, alkaline phosphatase, aspartate aminotransferase, alanine aminotransferase, $\gamma$-glutamyl transpeptidase, lactate dehydrogenase, uric acid (UA), blood urea nitrogen, creatinine, total cholesterol, triglyceride (TG), high-density lipoprotein cholesterol, low-density lipoprotein cholesterol, blood glucose, HbAlc, carcinoembryonic antigen and carbohydrate antigen 19-9 were analyzed.

Statistical analysis. A one-way analysis of variance was performed to analyze the association between the presence of diverticula and each variable. A $\chi^{2}$ test was used to determine the correlation between the presence of diverticula and age group, gender and UA levels $\geq 5.1 \mathrm{mg} / \mathrm{dl}$. A receiver operating characteristic (ROC) analysis was performed to determine the threshold values able to predict the presence of diverticula. Specificity and sensitivity were automatically calculated using an ROC program in the statistical software. $\mathrm{P}<0.05$ was considered to indicate statistical significance. JMP 10.0.2 software (SAS Institute, Cary, NC, USA) was used for the statistical analysis.

\section{Results}

To analyze the correlation between age and the presence of diverticula, the patients were divided into the following age groups: Group 20 (20-29 years old, 3 patients); group 30 (30-39 years old, 31 patients); group 40 (40-49 years old, 93 patients); group 50 (50-59 years, 125 patients); group 60 (60-69 years old, 508 patients); group 70 (70-79 years old, 597 patients); group 80 (80-89 years old; 154 patients) and group 90 (>90 years old; 9 patients) (Fig. 1). The incidence 
Table II. Association between gender and the presence of colon diverticula.

\begin{tabular}{lccr}
\hline & \multicolumn{2}{c}{ Colon diverticula, $\mathrm{n}$} & \\
\cline { 2 - 3 } Gender & Absent & Present & Total, $\mathrm{n}$ \\
\hline Male & 543 & 219 & 762 \\
Female & 605 & 153 & 758 \\
Total & 1148 & 372 & 1520 \\
\hline
\end{tabular}

Table III. Association between uric acid level and the presence of colon diverticula.

\begin{tabular}{lccc}
\hline & \multicolumn{2}{c}{ Colon diverticula, $\mathrm{n}$} & \\
\cline { 2 - 3 } Uric acid level & Absent & Present & Total, $\mathrm{n}$ \\
\hline High $(\geq 5.1 \mathrm{mg} / \mathrm{dl})$ & 99 & 49 & 148 \\
Low $(<5.1 \mathrm{mg} / \mathrm{dl})$ & 114 & 20 & 134 \\
Total & 213 & 69 & 282 \\
\hline
\end{tabular}

Table IV. Threshold values to predict the presence of colon diverticula.

\begin{tabular}{lcccc}
\hline $\begin{array}{l}\text { Blood } \\
\text { variable }\end{array}$ & AUC & $\begin{array}{c}\text { Threshold } \\
\text { value, mg/dl }\end{array}$ & $\begin{array}{c}\text { Sensitivity, } \\
\%\end{array}$ & $\begin{array}{c}\text { Specificity, } \\
\%\end{array}$ \\
\hline $\mathrm{Hb}$ & 0.56926 & 12400 & 76.5 & 34.1 \\
$\mathrm{TG}$ & 0.63512 & 146 & 47.5 & 75.3 \\
$\mathrm{UA}$ & 0.62105 & 5.1 & 71.0 & 53.5 \\
\hline
\end{tabular}

AUC, area under the (receiver operating characteristic) curve; $\mathrm{Hb}$, hemoglobin; TG, triglyceride; UA, uric acid.

of diverticula increased with advancing age, but no significant correlation was found by $\chi^{2}$ test $(\mathrm{P}=0.0643)$.

The experimental variables were compared to determine significant differences between patients with and without diverticula (Table I). Hb levels were lower in patients with diverticula compared with those without diverticula $(\mathrm{P}=0.0027)$. UA and TG levels were also higher in patients with diverticula ( $\mathrm{P}=0.0066$ and $\mathrm{P}=0.0136$, respectively).

Table II reports the $\chi^{2}$ test results comparing the prevalence of diverticula between male and female patients. Diverticula were more frequent in male patients than in female patients $(\mathrm{P}=0.0001)$. The mean ages of the male and female patients with diverticula were $69.2 \pm 11.0$ and $68.0 \pm 10.2$ years, respectively.

Table I demonstrates that UA levels were significantly higher in patients with diverticula compared with those without diverticula. To confirm these results, the patients were divided into two groups according to UA level, as follows: Patients with UA levels $\geq 5.1 \mathrm{mg} / \mathrm{dl}$ and those with UA levels $<5.1 \mathrm{mg} / \mathrm{dl}$. In the patient sample of the current

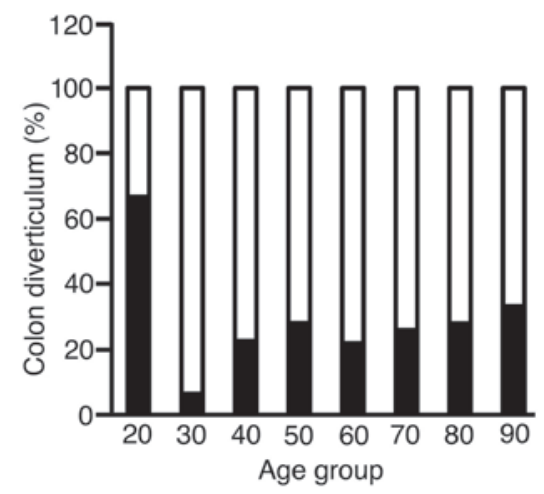

Figure 1. Prevalence of colon diverticula among different age groups. Patients were divided into different age groups. There were 3 patients in their twenties, which was significantly lower than the number of patients in the other age groups. White bar, patients without colon diverticula; black bar, patients with colon diverticula.

A

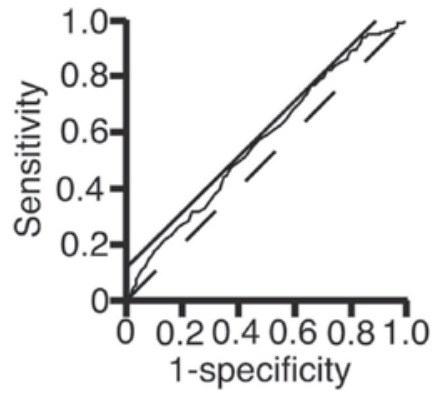

B

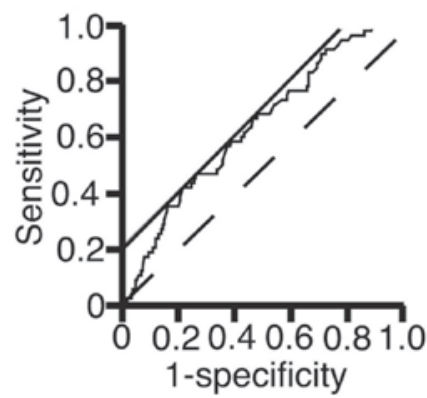

C

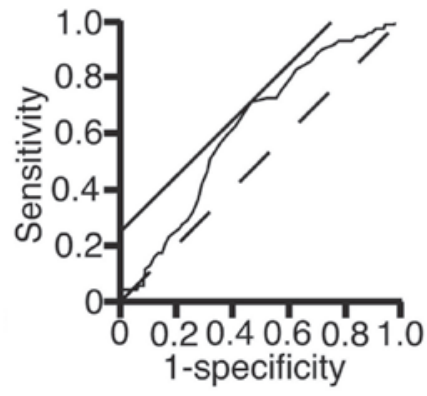

Figure 2. Receiver operating characteristic (ROC) analysis. The ROC analysis was performed to determine the threshold values of (A) hemoglobin, (B) triglycerides and (C) uric acid to predict the presence of colon diverticula. Solid straight line, a line with a slope of $45^{\circ}$ used to calculate the threshold; dashed line, reference line.

study, $5.1 \mathrm{mg} / \mathrm{dl}$ was the median UA level. The prevalence of diverticula was compared between the two groups (Table III); this was significantly higher in patients with UA levels $\geq 5.1 \mathrm{mg} / \mathrm{dl}$ than in those with UA levels $<5.1 \mathrm{mg} / \mathrm{dl}$ 
$\left(\mathrm{P}=0.0004 ; \chi^{2}\right.$ test). Diverticula were markedly more frequent in patients with UA levels $\geq 5.1 \mathrm{mg} / \mathrm{dl}$.

To address the possibility that the presence of diverticula could be predicted using laboratory test variables, an ROC analysis was performed (Fig. 2). The area under the curve, threshold value, sensitivity and specificity are presented in Table IV. The threshold values of the Hb, TG and UA levels were $12,400,146$ and $5.1 \mathrm{mg} / \mathrm{dl}$, respectively. The sensitivity of the $\mathrm{Hb}$ and UA levels at the threshold values was 76.5 and $71.0 \%$, respectively.

\section{Discussion}

The correlation between laboratory data, with the exception of age, and the presence of diverticula has not been previously reported. In the present study, the presence of diverticula was significantly associated with low Hb levels, and high TG and UA levels. A non-significant trend with increasing age was also revealed. The prevalence of diverticula may increase with advancing age due to structural changes in the colon wall $(10,13,14)$. To the best of our knowledge, the present study is the first to report an association between diverticula and low $\mathrm{Hb}$, high TG and high UA levels.

The current study revealed that the $\mathrm{Hb}$ levels were lower in patients with diverticula than in those individuals without; lower $\mathrm{Hb}$ levels were likely associated with the presence of diverticula as this is a major cause of lower gastrointestinal bleeding (15).

Higher TG levels are associated with metabolic syndrome $(16,17)$ and TG level decreases as metabolic syndrome improves following lifestyle changes (18). In the present study, high TG levels were associated with diverticula. These previous data, alongside the data from the current study, indicate that diverticula may be associated with metabolic syndrome. Foster et al (19) compared the prevalence of diverticula between patients with and without ischemic heart disease and demonstrated that diverticula occurred in 57 and $25 \%$ of patients, respectively. This indicated an association with ischemic heart disease, which itself has a known association with high TG levels (20). Previous studies, together with the present data, thus indicate that high TG levels may be associated with diverticula.

The data in the current study clearly suggested that the prevalence of diverticula was associated with higher UA levels; to the best of our knowledge, the current study presents the first report of this association. The molecular details, however, are not known. The data on TG and UA presented in the current study may suggest that a reduction in TG and UA levels decreases the risk of diverticula.

Fernández et al (21) reported that predicting colonoscopic outcomes is challenging when based on blood examination results alone. The sensitivity of the $\mathrm{Hb}$ level at $12,400 \mathrm{mg} / \mathrm{dl}$ was $76.5 \%$ in the current study, suggesting that low Hb levels may be due to diverticulum bleeding. A notable finding was that the threshold value of UA was $5.1 \mathrm{mg} / \mathrm{dl}$, the same value as the median.

To conclude, low Hb levels and high TG and UA levels are associated with the presence of diverticula. Therefore, colonoscopy may be recommended for patients with high TG and UA levels, in order to detect colon diverticula.

\section{References}

1. Meyers MA, Volberg F, Katzen B, Alonso D and Abbott G: The angioarchitecture of colonic diverticula. Significance in bleeding diverticulosis. Radiology 108: 249-261, 1973.

2. Wilkins T, Baird C, Pearson AN and Schade RR: Diverticular bleeding. Am Fam Physician 80: 977-983, 2009.

3. Humes DJ and Spiller RC: Review article: The pathogenesis and management of acute colonic diverticulitis. Aliment Pharmacol Ther 39: 359-370, 2014.

4. Marion Y, Lebreton G, Le Pennec V, Hourna E, Viennot S and Alves A: The management of lower gastrointestinal bleeding. J Visc Surg 151: 191-201, 2014.

5. Jansen A, Harenberg S, Grenda U and Elsing C: Risk factors for colonic diverticular bleeding: A Westernized community based hospital study. World J Gastroenterol 15: 457-461, 2009.

6. Tsuruoka N, Iwakiri R, Hara M, Shirahama N, Sakata Y, Miyahara K, Eguchi Y, Shimoda R, Ogata S, Tsunada S, et al: NSAIDs are a significant risk factor for colonic diverticular hemorrhage in elder patients: Evaluation by a case-control study. J Gastroenterol Hepatol 26: 1047-1052, 2011.

7. Aldoori WH, Giovannucci EL, Rimm EB, Wing AL and Willett WC: Use of acetaminophen and nonsteroidal anti-inflammatory drugs: A prospective study and the risk of symptomatic diverticular disease in men. Arch Fam Med 7: 255-260, 1998.

8. Weizman AV and Nguyen GC: Diverticular disease: Epidemiology and management. Can J Gastroenterol 25: 385-389, 2011.

9. Afshar S and Kurer MA: Laparoscopic peritoneal lavage for perforated sigmoid diverticulitis. Colorectal Dis 14: 135-142, 2012.

10. Granlund J, Svensson T, Olén O, Hjern F, Pedersen NL, Magnusson PK and Schmidt PT: The genetic influence on diverticular disease - a twin study. Aliment Pharmacol Ther 35: 1103-1107, 2012.

11. Crowe FL, Appleby PN, Allen NE and Key TJ: Diet and risk of diverticular disease in Oxford cohort of European Prospective Investigation into Cancer and Nutrition (EPIC): Prospective study of British vegetarians and non-vegetarians. BMJ 343: d4131, 2011.

12. Peery AF, Barrett PR, Park D, Rogers AJ, Galanko JA, Martin CF and Sandler RS: A high-fiber diet does not protect against asymptomatic diverticulosis. Gastroenterology 142: 266-272.e1, 2012.

13. Song JH, Kim YS, Lee JH, Ok KS, Ryu SH, Lee JH and Moon JS: Clinical characteristics of colonic diverticulosis in Korea: A prospective study. Korean J Intern Med 25: 140-146, 2010.

14. Heise CP: Epidemiology and pathogenesis of diverticular disease. J Gastrointest Surg 12: 1309-1311, 2008.

15. Wilkins T, Khan N, Nabh A and Schade RR: Diagnosis and management of upper gastrointestinal bleeding. Am Fam Physician 85: 469-476, 2012.

16. Tomizawa M, Kawanabe Y, Shinozaki F, Sato S, Motoyoshi Y, Sugiyama T, Yamamoto S and Sueishi M: Elevated levels of alanine transaminase and triglycerides within normal limits are associated with fatty liver. Exp Ther Med 8: 759-762, 2014.

17. Tomizawa M, Kawanabe Y, Shinozaki F, Sato S, Motoyoshi Y, Sugiyama T, Yamamoto S and Sueishi M: Triglyceride is strongly associated with nonalcoholic fatty liver disease among markers of hyperlipidemia and diabetes. Biomed Rep 2: 633-636, 2014.

18. Yamaoka $\mathrm{K}$ and Tango T: Effects of lifestyle modification on metabolic syndrome: A systematic review and meta-analysis. BMC Med 10: 138, 2012.

19. Foster KJ, Holdstock G, Whorwell PJ, Guyer P and Wright R: Prevalence of diverticular disease of the colon in patients with ischaemic heart disease. Gut 19: 1054-1056, 1978.

20. Lisak M, Demarin V, Trkanjec Z and Basić-Kes V: Hypertriglyceridemia as a possible independent risk factor for stroke. Acta Clin Croat 52: 458-463, 2013.

21. Fernández E, Linares A, Alonso JL, Sotorrio NG, de la Vega J, Artimez ML, Giganto F, Rodríguez M and Rodrigo L: Colonoscopic findings in patients with lower gastrointestinal bleeding send to a hospital for their study. Value of clinical data in predicting normal or pathological findings. Rev Esp Enferm Dig 88: 16-25, 1996. (In Spanish). 